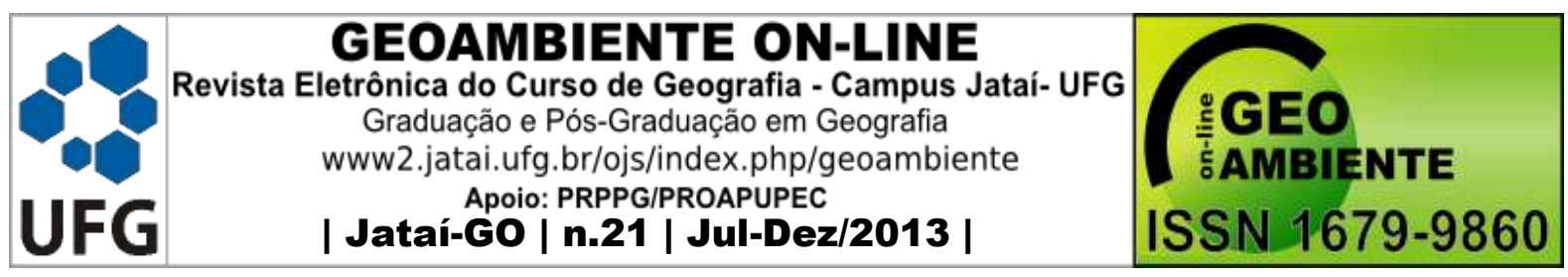

\title{
APONTAMENTOS DE EPISTEMOLOGIA AMBIENTAL
}

\author{
Munir José Felício
}

(Universidade do Oeste Paulista, Docente do programa de mestrado em Meio Ambiente e Desenvolvimento Regional, munir@unoeste.br)

\section{Resumo}

A alienação e o pensamento fetichizado podem retirar do ser humano a capacidade de sonhar, de ter utopia, principalmente por não identificar a aparência fenomênica da sua essência. Indistinção como essa obstaculiza compreender a gênese da questão ambiental como consequiência inexorável do avanço capitalista. Por isso uma das questões que será debatida nesse texto consiste em refletir sobre o seguinte questionamento: até que ponto a questão ambiental é conseqüência do avanço do modo de produção capitalista? Esse debate está presente na primeira parte desse texto entendendo a questão ambiental como questão política. $\mathrm{Na}$ segunda parte estão reunidas diversas análises as quais visam compreender o engendramento da cultura burguesa como componente indispensável do modo de produção capitalista. E, na terceira parte, procura traçar pontos de contato entre a epistemologia ambiental e a teoria lukacsiana visando demonstrar a insustentável racionalidade da economia de mercado que é impulsionada pelo pensamento fetichizado e que será superado na medida em que se construir uma epistemologia ambiental concebendo os impactos ambientais como conseqüência do avanço capitalista. Conclui-se, portanto, a urgente tarefa de fazer emergir a epistemologia ambiental problematizando a histórica e insustentável racionalidade de mercado, bem como incorporá-la ao debate sobre o desenvolvimento elegendo novos modelos interpretativos.

Palavras-chave: questão ambiental; pensamento fetichizado; avanço capitalista

\section{Abstract}

\section{NOTES OF ENVIRONMENTAL EPISTEMOLOGY}

\footnotetext{
Artigo recebido para publicação em 09 de Novembro de 2013

Artigo aprovado para publicação em 22 de Dezembro de 2013
} 


\begin{tabular}{|c|c|c|}
\hline & $\begin{array}{c}\text { GEOAMBIENTE ON-LINE } \\
\text { Revista Eletrônica do Curso de Geografia - Campus Ja } \\
\text { Graduacăo e Pós-Graduaçăo em Geografia } \\
\text { www2.jatai.ufg.br/ojs/index.php/geoambient } \\
\text { Apoio: PRPPG/PROAPUPEC } \\
\text { | Jataí-GO | n.21 | Jul-Dez/2013 | }\end{array}$ & $\begin{array}{l}\text { BIENTE } \\
1679-9860\end{array}$ \\
\hline
\end{tabular}

The alienation and the fetishized thought can take from the human being the ability to dream, to be utopic, principally for not identifying the phenomenal aspect of its essence. Indistinctness such as this complicates the understanding that the environmental issue is a consequence of the inexorable advance of capitalism. One of the ideas that is going to be discussed in this text consists in reflecting this question: until which point is the environmental issue a consequence of the advance in capitalism's production way? This debate is on the first part of this text, discussing the environmental issue as a political issue. In the second part of the text, there are some analysis, in which try to understand the engendering of the bourgeoisie culture as an indispensable component of the capitalist's productive way. And, in the third part, try to connect the environmental epistemology and the Lukacsian theory, to show the unsustainable rationality of the market's economy, that's driven by the fetishized thought and that will be overcome as according as we built an environmental epistemology considering the environmental issues as a consequence of the capitalism advance. Therefore, we conclude with the urgent task of emerging environmental epistemology questioning the historical and unsustainable market rationality, as well as incorporating it into the debate on development debate by electing new interpretative models.

Key-Words: Environmental issue; Fetishized thought; Capitalism Advance

\section{Resumen}

\section{APUNTAMIENTOS DE EPISTEMOLOGIA AMBIENTAL}

La alienación y el pensamiento hechizado pueden retirar del ser humano la capacidad de soñar, de tener utopía, principalmente por no identificar la apariencia fenoménica de su esencia. Indistinción como esa obstaculiza comprender la génesis de la cuestión ambiental como consecuencia inexorable del avanzo capitalista. Por eso una de las cuestiones que será debatida en ese texto consiste en reflexionar sobre el siguiente cuestionamiento: ¿hasta qué punto la cuestión ambiental es consecuencia del avanzo del modo de producción capitalista? Ese debate está presente en la primera parte de ese texto entendiendo la cuestión ambiental como facto político. En la segunda parte están reunidas diversas análisis las cuales visan comprender el engendramiento de la cultura burguesa como componente indispensable del modo de producción capitalista. Y, en la tercera parte, busca trazar puntos de contacto entre la 


\begin{tabular}{|c|c|c|}
\hline & $\begin{array}{c}\text { GEOAMBIENTE ON-LINE } \\
\text { Revista Eletrônica do Curso de Geografia - Campus Ja } \\
\text { Graduacăo e Pós-Graduaçăo em Geografia } \\
\text { www2.jatai.ufg.br/ojs/index.php/geoambient } \\
\text { Apoio: PRPPG/PROAPUPEC } \\
\text { | Jataí-GO | n.21 | Jul-Dez/2013 | }\end{array}$ & $\begin{array}{l}\text { BIENTE } \\
1679-9860\end{array}$ \\
\hline
\end{tabular}

epistemología ambiental y la teoría lukacsiana visando demostrar la insustentable racionalidad de la economía de mercado que es impulsada por el pensamiento hechizado y que será superado en la medida en que construirse una epistemología ambiental concibiendo los impactos ambientales como consecuencia del avanzo capitalista. Se concluye, por lo tanto, la urgencia tarea de hacer emerger la epistemología ambiental problematizando la histórica e insustentable racionalidad de mercado, bien como incorporarla al debate sobre el desenvolvimiento eligiendo nuevos modelos interpretativos.

Palabras clave: cuestión ambiental; pensamiento hechizado; avanzo capitalista.

\section{Introdução}

A questão ambiental pode ser considerada atualmente a questão de todas as questões. Há quem a considere como o centro da crise do conhecimento e da civilização (LEFF, 2000, 2007); como o centro da crise do sistema-mundo cujo desenvolvimento encontra-se em formação há 5.000 anos (DUSSEL, 2000); e, portanto precisar ser tratada com a devida complexidade "no pensamento cientifico, no pensamento epistemológico e no pensamento filosófico" (MORIN, 2010, p. 175).

A complexidade da questão ambiental como questão de todas as questões faz as decisões científicas ganharem caráter de imprescindibilidade dada a necessidade de alterar os rumos, de tal forma que garanta a sobrevivência humana. A aproximação de um colapso ou do ecocídio como suicídio coletivo, não deixará o horizonte, a não ser que a ciência enfrente essa complexidade com os recursos que tem, ainda que muitos dos problemas ambientais que se presencia hoje ou que poderão ocorrer em breve sejam irreversíveis em curto prazo. Trata-se da vida humana "que não é um conceito, uma idéia, nem um horizonte abstrato, mas o modo de realidade de cada ser humano concreto, condição absoluta da ética e exigência de toda libertação" (DUSSEL, 2000, P. 11). De toda ciência e de todas as nações.

As três partes desse texto almejam participar dessas reflexões discutindo, na primeira parte, a questão ambiental como questão política, por considerar o conjunto de danificações ambientais as consequências inexorávies da expansão do modo de produção capitalista. $\mathrm{Na}$ segunda parte, a reflexão demonstrará a proeminência convexa da cultura burguesa com o desenvolvimento desse modo de produção sendo impulsionado pela ditadura da mercadoria que nutre o pensamento fetichizado. Na terceira parte se discutirá as alternativas de superação 


\begin{tabular}{|c|c|c|}
\hline & $\begin{array}{c}\text { GEOAMBIENTE ON-LINE } \\
\text { Revista Eletrônica do Curso de Geografia - Campus Ja } \\
\text { Graduacăo e Pós-Graduaçăo em Geografia } \\
\text { www2.jatai.ufg.br/ojs/index.php/geoambient } \\
\text { Apoio: PRPPG/PROAPUPEC } \\
\text { | Jataí-GO | n.21 | Jul-Dez/2013 | }\end{array}$ & $\begin{array}{l}\text { BIENTE } \\
1679-9860\end{array}$ \\
\hline
\end{tabular}

do pensamento fetichizado ao procurar possíveis pontos de contato da epistemologia ambiental que se almeja construir com esse texto com a teoria lukacsiana.

\section{Questão ambiental como questão política}

A questão ambiental, como questão política, abrange um conjunto de danificações ambientais, algumas irreversíveis, em conseqüência da expansão do modo de produção capitalista colocando o futuro das gerações em estado de alerta. Trata-se da destruição ou de aniquilamento dos serviços ambientais fundamentais para o desenvolvimento da vida humana. Aniquilamento manifestado pelo efeito estufa, pelo aquecimento global, pela perda dos recursos naturais, pela desertificação, pelo crescimento demográfico acelerado e desorganizado,pela chuva ácida, entre outros.

A enorme gravidade ecológica desses impactos é suficiente para se constatar que mais da metade da área original das florestas do mundo foi convertida para outros usos. Desmatamento que compromete os principais serviços do ecossistema como a proteção das bacias hidrográficas, a proteção do solo contra a erosão o que interfere, significativamente, no ciclo das águas, resultando em grandes perdas de biodiversidade.

Esses aniquilamentos afetam a essência da natureza por ser ela a responsável pelo desenvolvimento de espécies selvagens, verdadeiros fornecedores de serviços gratuítos aos seres humanos que podem ser muito dispendiosos, e em muitos casos impossíveis de serem produzidos, sem o devido habitat natural. São funções indispensáveis como as que exercem as minhocas na regeneração do solo e na manutenção de sua textura, a proliferação das bactérias do solo que fixam o nitrogênio, nutriente essencial para as plantações, o trabalho profícuo com as polinizações executadas pelas abelhas e outros insetos.

Desde a década de 70 do século XX as conferências mundiais chamam a atenção para a insustentabilidade do modelo de desenvolvimento em vigor no globo. São questões políticas tanto a questão ambiental quanto o modelo de desenvolvimento, por isso as discussões sobre ambas têm, necessariamente, caráter político em que pese seus aspectos econômicos. É importante discutir essa complexidade para tentar compreender de que forma a questão ambiental pode ser um dos produtos do modelo de desenvolvimento. Vários pesquisadores se debruçaram sobre os desdobramentos da problemática ambiental procurando contribuir com suas análises como fizeram Leff(2000) e Sen (2008). 


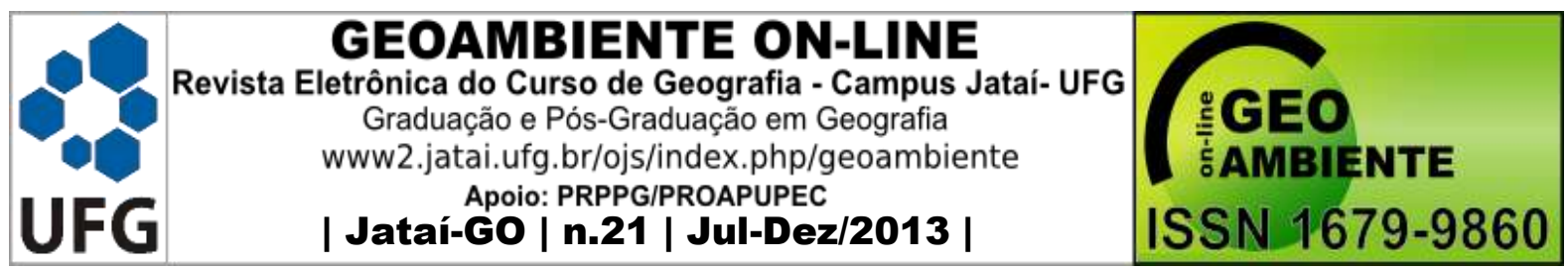

Para Leff (2000) a crise do conhecimento e a crise de civilização que se instalaram no último terço do século XX e que se desenvolveram no início do terceiro milênio avançaram por causa do "fracionamento do conhecimento e pela degradação do ambiente, marcados pelo logocentrismo da ciência moderna e pelo transbordamento da economização do mundo guiado pela racionalidade tecnológica e pelo livre mercado" (LEFF, 2000, p. 19). Na complexidade e interdisciplinariedade do saber ambiental está imbricada a questão social advinda da explosão demográfica e desorganizada simultaneamente com o aumento da perspectiva de vida percebida desde a década de 50 do século XX.

A questão econômica gerada com o avanço do capitalismo que se desenvolve sobre duas bases fundamentais - o processo de urbanização e de industrialização - e que se expande cada vez saqueando os recursos naturais e, avançando sobre a riqueza dos ecossistemas para convertê-los em valor de troca e coisificar o mundo e fetichizando as relações sociais. Nessa reflexão epistemológica e metodológica Leff (2000) alerta que a civilização do conhecimento é

ao mesmo tempo, a sociedade do desconhecimento, da alienação generalizada, da deserotização do saber e o desencantamento do mundo (a sociedade dos poetas mortos; uma sociedade sem propósito, sem imaginação, sem utopia, sem futuro). Nunca antes na História houve tantos seres humanos que desconhecessem tanto e estivessem tão excluídos dos processos e das decisões que determinam suas condições de existência; nunca antes houve tanta pobreza, tanta gente alienada de suas vidas, tantos saberes subjugados, tantos seres que perderam o controle, a condução e o sentido de sua existência; tantos homens e mulheres desempregados, desenraizados de seus territórios, desapropriados de suas culturas e de suas identidades. Nessa civilização supercientificada e "hipertecnologizada", tanto os que dominam como os que são dominados, se encontram alienados de seus mundos de vida, em um mundo no qual a incerteza, o risco e o descontrole aumentam proporcionalmente ao aumento dos efeitos de domínio da ciência sobre a natureza (LEFF, 2000, p. 23. Grifos no original)

Para Leff (2000) é urgente ampliar a discussão sobre a questão ambiental reconhecendo que a solução dessa problemática implica mudanças na organização do conhecimento, reorganizando formatos de pesquisa e ensino, fundamentados por uma visão sistêmica da realidade e com base em métodos interdisciplinares que questionem as formas históricas do conhecimento como raiz e causa de exploração dos recursos naturais e da submissão das culturas. Ele alerta que

O socialismo cientifico não questionou o vínculo do ser ao conhecimento e sua dominação da natureza. Foram Nietzsche e Heiddegger - e mais tarde os filósofos da Escola de Frankfurt - que traçaram o perfil de uma crítica radical das raízes do 


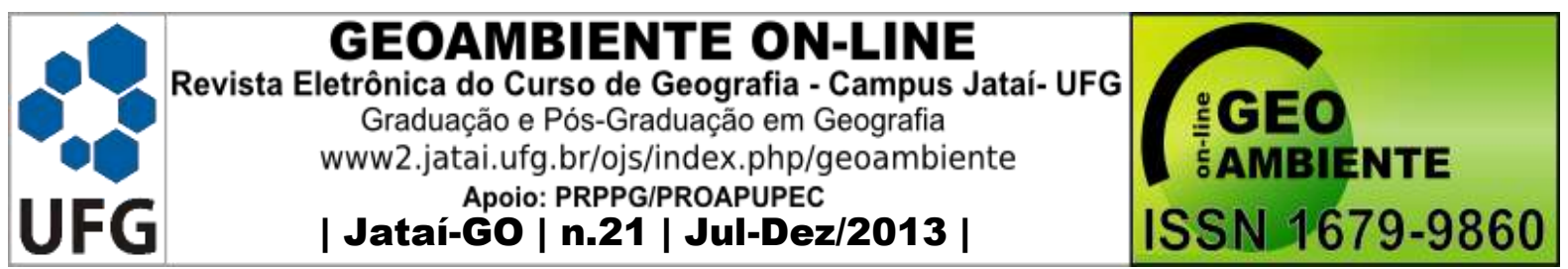

pensamento metafísico, da ciência positivista e da racionalidade tecnológica em sua vontade universalidade, homogeneidade e unidade do conhecimento, de objetivação e coisificação do ser, que geraram a atual globalização unidimensional, regida e valorizada pelo modelo econômico: a "sobreconomização" do mundo (LEFF, 2000, p. 24).

A necessidade em pensar criticamente como forma de encontrar novos horizontes do saber evitando assim a "falsa" dicotomia entre a ciência boa que só traz benefícios e ciência má que só traz prejuízos, o que mereceu as criticas de Morin (2010, p.15-36), consiste numa epistemologia ambiental, que para Leff (2007) tem a finalidade de questionar o conhecimento a partir de fora do campo da positividade por entender que

A crise ambiental é uma crise do conhecimento: da dissociação entre o ser e o ente à
lógica autocentrada da ciência e ao processo de racionalização da modernidade
guiado pelos imperativos da racionalidade econômica e instrumental. O saber que
emerge dessa crise no campo de externalidade das ciências se filtra entre as
estruturas teóricas e as malhas discursivas do conhecimento moderno; a partir dali,
questiona os paradigmas estabelecidos, abrindo as portas para o saber negado. O
saber ambiental vai derrubando certezas e abrindo os raciocínios fechados que
expulsam o ambiente dos círculos concêntricos do conhecimento. A epistemologia
ambiental confronta o projeto positivista (universal, objetivo) do conhecimento e
deslinda as estratégias de poder que se entrelaçam nos paradigmas científicos e na
racionalidade da modernidade. Esta é sua coerência estratégica. A epistemologia
ambiental é uma política do saber que busca a sustentabilidade da vida (LEFF, 2007,
p. 13-14).

O desenvolvimento como liberdade exige a retirada de todas as formas de privação de liberdade como pobreza, tirania, negligência dos serviços públicos aumentando o envolvimento e a participação de um número cada vez maior de pessoas transformando-as em agente livre e sustentável que "emerge como um motor fundamental do desenvolvimento. A livre condição de agente não só é, em si, uma parte 'constitutiva' do desenvolvimento, mas também contribui para fortalecer outros tipos de condições de agentes livres” (SEN, 2008, p. 19).

Agrupam-se ao redor das fomes coletivas outras formas de privação de liberdade tais como educação funcional, emprego remunerado, a desigualdade entre mulheres e homens, entre outras, as quais retiram o potencial das pessoas ou minimizam seu dinamismo para cuidar de si mesmo e de interagir economicamente umas com as outras. Sen (2008) enfatiza que

A liberdade individual é essencialmente um produto social, e existe uma relação de mão dupla entre (1) as disposições sociais que visam expandir as liberdades individuas e (2) o uso de liberdades individuais não só para melhor a vida de cada um, mas também para tornar as disposições sociais mais apropriadas e eficazes (SEN, 2008, p. 46). 


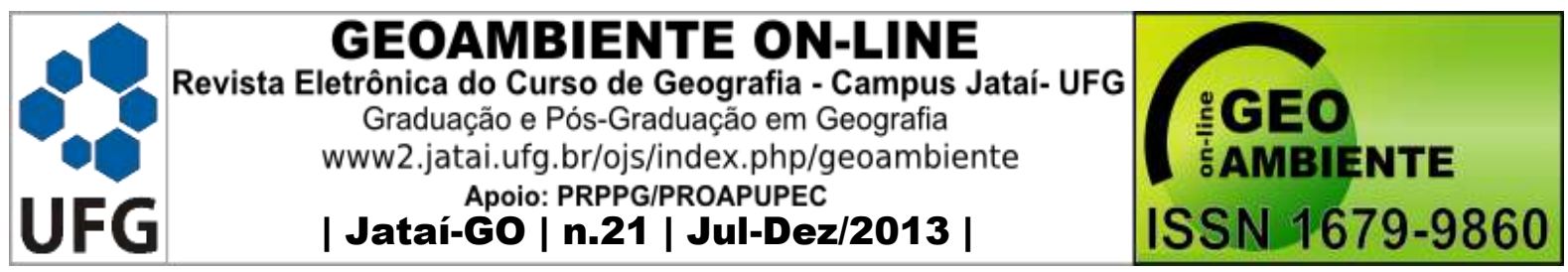

A sustentabilidade da vida não pode permanecer com a coexistência de dois mundos como explica Sen (2008): o da opulência e o da privação. O mundo de opulência sem precedentes propicia às pessoas hoje viverem "em média muito mais tempo do que no passado, [...], entretanto, vivemos igualmente em um mundo de privação, destituição e opressões extraordinárias" (SEN, 2008, p. 9). A coexistência desses dois mundos se deve a economia capitalista. $\mathrm{O}$ modo peculiar de reprodução do capital e seu avanço utilizando de forma ilimitada os recursos naturais e alterando, por onde passa as relações sociais, engendrando uma cultura que lhe permita esquadrinhar todo o globo a fim de obter os melhores e os mais baratos meios de produção.

\section{A cultura burguesa e o modo de produção capitalista}

São análises como as de Kautsky (1986) aquelas que, conseguem desfazer o incensamento ao modelo de desenvolvimento capitalista por impulsionar discussões científicas nos meios acadêmicos, sociais e políticos, ao procurar compreender as transformações seminais, cuja gênese encontra-se na formação e no desenvolvimento do modelo de produção capitalista e de sua decorrente cultura.

Kautsky (1986, p.13) ao procurar compreender essas transformações esclareceu, a partir de sua própria experiência, a importância do teórico "que deseja pesquisar as leis fundamentais que regem essa sociedade não deve permitir que a abundância de fenômenos particulares o iluda. Terá de pesquisar o modo de produção capitalista e atentar para o que nele existe de peculiar, [...]".

Kautsky (1986) e Luxemburg (1985) estão entre os pesquisadores que deram prosseguimento, logo após a morte de Marx, às análises iniciadas por ele na tentativa de desvendar a problemática que evolve a reprodução do capital social. Suas análises convergiram nas formas pré-capitalistas de produção agrícola tentando compreender se elas fazem parte, ou não, do desenvolvimento capitalista, e quais funções continuavam a desempenhar com o avanço do capital, uma vez que o modo de produção capitalista não era a única forma de produção existente como esclarece Kautsky:

Quando se pretende estudar a questão agrária segundo o método de Marx não se deve apresentar apenas a questão do futuro que teria eventualmente a pequena empresa agrícola; mais do que isso, nós temos que examinar todas as transformações que sofre a agricultura nas várias fases do modo de produção capitalista. Devemos verificar se o capital se apodera da agricultura, como o faz, se a revoluciona, se torna insustentável as velhas formas de produção e propriedade e se acarreta ou não a 


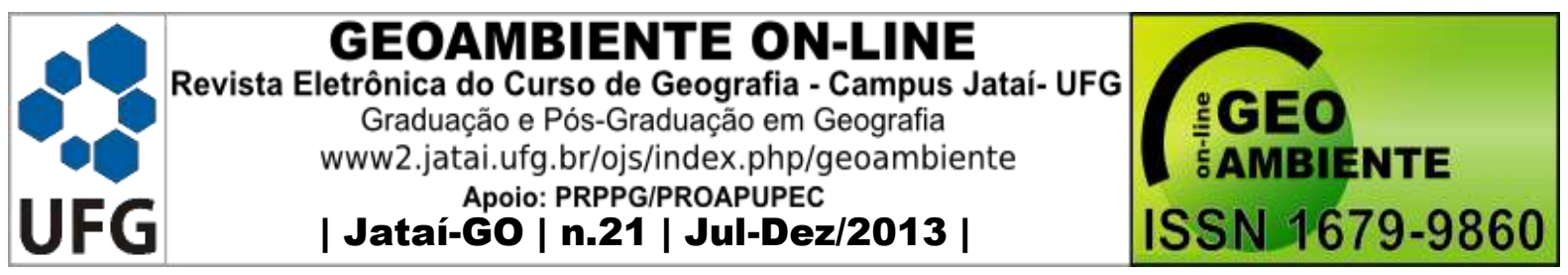

necessidade de novas formas. Apenas depois de termos essas questões respondidas é que nós poderemos ver se a teoria marxista é aplicável à agricultura, ou não, e se a supressão da propriedade privada esbarra na questão dos meios de produção, ou seja, na terra que, entre os meios de produção, é o mais nobre (KAUTSKY, 1986, p. 15).

As análises de Kautsky (1986) sobre a questão agrária são seminais e ainda impulsionam pesquisas sobre os velhos e os novos elementos das relações entre o capital e o campesinato como fez Felício (2011) ao analisar os processos de integraçãosubalternidade/resistência e destruição do campesinato.

Luxemburg (1985) ao analisar a reprodução do capital e seu meio expõe que "o esquema marxista da reprodução ampliada não consegue explicar-nos, pois, o processo de acumulação da maneira como ele realmente ocorre e como se impõe historicamente" (LUXEMBURG 1985, p. 239). O processo de acumulação perene se efetiva pelo fato do capital não admitir nenhuma limitação, por isso

\begin{abstract}
A questão dos elementos materiais da acumulação do capital está longe de encontrar-se resolvida pela forma material da mais-valia de cunho capitalista; essa questão, pelo contrário, vem-se transformando em outra totalmente diferente. Para o emprego produtivo da mais-valia realizada é necessário que o capital disponha cada vez mais do globo terrestre todo a fim de ter uma oferta qualitativa e quantitativamente ilimitada no condizente aos respectivos meios de produção (LUXEMBURG 1985, p. 246).
\end{abstract}

Baseada nessas razões, Luxemburg (1985) entende que sempre houve duas maneiras distintas do capital transacionar para poder transformar, a mais-valia em sua forma pura de valor, em forma produtiva de capital, "transações que ocorrem entre a produção capitalista e o mundo não-capitalista que o circunda" (LUXEMBURG 1985, p. 247) como será visto mais adiante com maiores detalhes.

As análises de Kautsky (1986) e Luxemburg (1985) visavam elucidar o perfil peculiar da reprodução da sociedade capitalista refletindo sobre essa forma distinta e particular de produção e compará-las às outras formas históricas. Somam-se a essas, a contribuição de Arrighi (2009) cuja contribuição procurará demonstrar a necessidade do capital em se apropriar, de diferentes formas e lugares, dos recursos jurídicos e políticos para ultrapassar os limites que lhe são impostos. O capital sempre encontra um modo peculiar de se reproduzir. Trata-se das artimanhas utilizadas para estruturar o sistema capitalista e evidenciar, por conseguinte, a interdependência entre a formação de um sistema, cada vez mais mundializado, e, a criação de Estados Nacionais.

As análises de Arrighi (2009) pretendem compreender as mudanças na configuração 


\begin{tabular}{|c|c|c|}
\hline & $\begin{array}{c}\text { GEOAMBIENTE ON-LINE } \\
\text { Revista Eletrônica do Curso de Geografia - Campus Ja } \\
\text { Graduacăo e Pós-Graduaçăo em Geografia } \\
\text { www2.jatai.ufg.br/ojs/index.php/geoambient } \\
\text { Apoio: PRPPG/PROAPUPEC } \\
\text { | Jataí-GO | n.21 | Jul-Dez/2013 | }\end{array}$ & $\begin{array}{l}\text { BIENTE } \\
1679-9860\end{array}$ \\
\hline
\end{tabular}

espacial dos processos de acumulação do capital demonstrando que o capitalismo e os Estado Nacionais cresceram juntos, como que gêmeo siamês. Arrighi (2009) desenvolveu uma análise histórica dividindo a expansão capitalista em quatro ciclos sistêmicos. O primeiro deles se estabeleceu por intermédio das hegemonias do capitalismo mercantil a partir do século XV na Itália, tendo como referências históricas quatro centros de comando: Veneza, Florença, Gênova e Milão, em que "o sistema mundial moderno se formou e se expandiu com base em recorrentes reestruturações fundamentais, lideradas e governadas por sucessivos Estados hegemônicos" (ARRIGHI, 2009, p. 30-31).

O segundo ciclo sistêmico se reorganizou por intermédio das "redes comerciais e financeiras que a oligarquia capitalista holandesa havia tecido a partir dos impérios ultramarinos e coloniais" (ARRIGHI 2009, p. 30-31). Por conseguinte, a riqueza e o poder da oligarquia capitalista deram à Holanda a possibilidade de ocupar o lugar da hegemonia capitalista italiana. A expansão do capital impõe uma reestruturação geopolítica transformando pequenos territórios "em imensos continentes de poder, buscando acumular apenas riqueza, em vez de adquirir mais territórios e súditos" (ARRIGHI 2009, p. 39). Portanto, a busca do capital era muito mais intensa quanto aos aparatos jurídicos e políticos, do que territoriais.

O terceiro ciclo sistêmico de acumulação capitalista transforma Londres em novo centro mundial cuja finalidade consistia em dirigir e coordenar as finanças mundiais no início da década de 1780, principalmente pela expansão fenomenal da indústria britânica. Tal expansão estava na dependência ela faria por "novos usos para os produtos baratos que seus novos grandes fornos eram capazes de produzir", salienta Arrighi (2009, p. 164). As construções das ferrovias geraram demandas entre as organizações governamentais e empresariais do mundo inteiro. "Entre 1845-49 e 1870-75, as exportações britânicas de ferro e aço para ferrovias mais do que triplicaram, enquanto as de maquinaria aumentaram nove vezes" (ARRIGHI, 2009, p. 165).

O quarto ciclo sistêmico de acumulação de capital é o norte-americano que fora marcado pela expansão financeira a ser desenvolvida no fim do século XIX. Arrighi (2009) prossegue com a análise dos processos mundiais de acumulação de capital tendo como periodização aproximada e preliminar a duração de mais de um século. "A capacidade norteamericana de administrar o sistema monetário mundial continuava nitidamente inferior à capacidade residual da própria Grã-Bretanha” (ARRIGHI, 2009, p. 280). Todavia, explica 


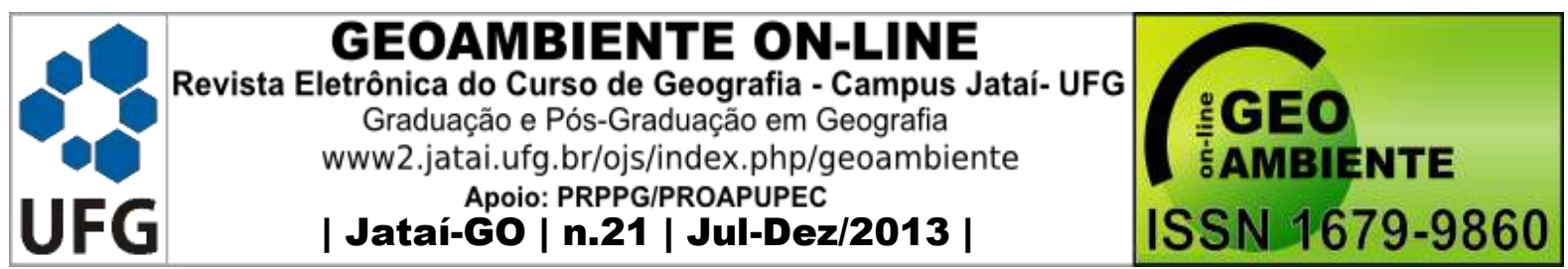

Arrighi, que

No fim da Segunda Guerra Mundial, já estavam estabelecidos os principais contornos desse novo sistema monetário mundial: em Bretton Woods foram estabelecidas as bases do novo sistema monetário mundial; em Hiroshima e Nagasaki, novos meios de violência haviam demonstrado quais seriam os alicerces militares da nova ordem; em San Francisco, novas normas e regras para a legitimação da gestão do Estado e da guerra tinham sido explicitadas na Carta das Nações Unidas (ARRIGHI, 2009, p. 283).

Os quatro ciclos sistêmicos de acumulação capitalista podem proporcionar compreensão de que a expansão do capital foi profícuo devido à sua força vital cujo fluxo aumenta o poder da nação, da força militar que ela tem e da capacidade para se impor, como descreve Harvey (2010), "capital is the lifeblood that flows through the body polític of all those societies we call capitalist, spreading out, sometimes as a trickle and other times as a flood, into every nook and cranny of the inhabited world (HARVEY, 2010, p. vi)". (Capital é a força vital que circula totalmente no corpo político de todas aquelas sociedades que nós chamamos capitalista, expandindo-se, ás vezes como um pingo e outras vezes como um dilúvio, na direção de todos os ângulos e aberturas do mundo habitado). (Tradução do próprio autor).

O desafio impulsionado por intermédio das análises de Luxemburg (1985) é ampliado mediante o reconhecimento de que a questão ambiental ainda não foi devidamente incorporada como parte inerente do debate sobre o desenvolvimento. Permanecem muito precárias, principalmente na América Latina, as teorias, as metodologias e os modelos interpretativos construídos pela ciência, como salienta Sóglio (2009):

\footnotetext{
Nos nossos países latino-americanos vivemos ainda uma disputa por crescimento econômico, justiça social e preservação cultural colocando a questão ambiental em terceiro ou quarto plano, como se fosse possível separar domínios e dimensões quando falamos em evolução ou desenvolvimento. A deterioração ambiental não nos permite adiar mais a sua incorporação ao cenário do desenvolvimento. Entretanto, na academia, ao admitir a incorporação da problemática ambiental como parte do debate sobre o desenvolvimento, as dificuldades são muitas, pois faltam teorias, metodologias e modelos que possam cumprir esse papel, [...] (SOGLIO, 2009, p. 313).
}

Esses apontamentos de epistemologia ambiental que buscam pontos de contato com a teoria lukacsiana ambicionam também participar dos esforços empreendidos por importantes pesquisadores como Carson (2013); Morin (2010); Leff (2007); Sachs (2008); Sampaio (2010) entre outros, visando enfrentar as dificuldades evidenciadas por Sóglio (2009). As análises de Carson (2013) são referencias seminais desde 1958 com "Primavera Silenciosa" por elucidar a insensatez e brutalidade do capital na depredação dos recursos naturais. O 


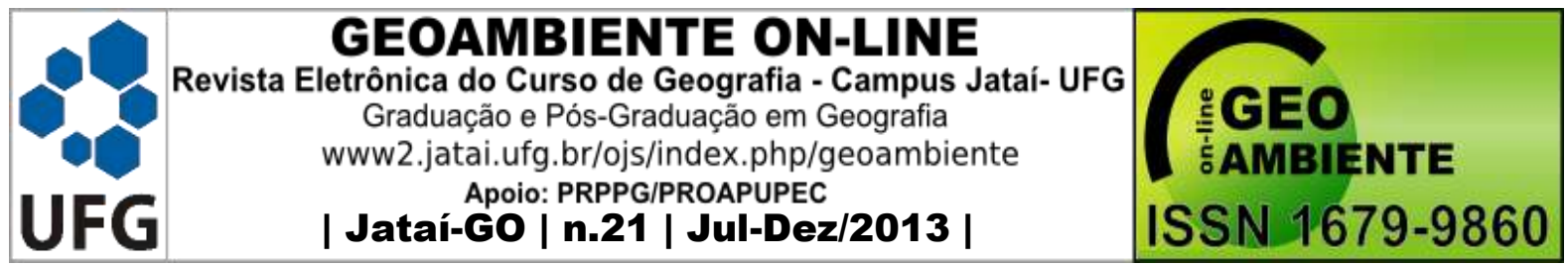

capital tem se mostrado como um grande saqueador e depredador dos recursos naturais e, de fato, Carson (2013) demonstrou que ele não admite que lhe imponham limites. As contribuições dela auxiliam compreender aquilo que outrora havia demonstrado teoricamente Luxemburg (1985), ou seja, de que forma o capital usa ilimitadamente de todos os recursos do meio ambiente. De modo que a junção da teoria de Luxemburg (1985) com as descrições de Carson (2013) conseguem lançar luzes para ampliar a compreensão da devastação provocada pelo capital, verificando a ferocidade das forças capitalistas das indústrias de inseticidas químicos:

\begin{abstract}
À medida que o ser humano avança rumo a seu objetivo proclamado de conquistar a natureza, ele vem escrevendo uma deprimente lista de destruições, dirigidas não só contra a Terra em que ele habita como também contra os seres vivos que a compartilham com ele. A história dos séculos recentes tem suas páginas negras - a matança do búfalo nas planícies do Oeste, o massacre das aves marinhas efetuado pelos caçadores mercenários, o quase extermínio das garças por causa de sua plumagem. Agora, a essas devastações e outras semelhantes, estamos acrescentando um novo capítulo e um novo tipo de devastação - matança direta de pássaros, mamíferos, peixes e, na verdade, praticamente todas as formas de vida selvagem por inseticidas químicos pulverizados indiscriminadamente sobre a terra (CARSON, 2013, p. 83).
\end{abstract}

As importantes análises de Carson (2013) que ainda servem para ilustrar as concepções analíticas de Luxemburg (1985) também demonstram a necessidade e a importância na busca de pontos de contato entre a epistemologia ambiental e a teoria lukacsiana. Trata-se de fazer emergir alternativas críveis e viáveis com a urgente desconstrução do pensamento fetichizado como explica Lukács (2007),

\begin{abstract}
A economia de Marx está trespassada de espírito científico que em seu devir consciente e crítico, jamais renuncia ao sentido ontológico, que melhor como regra crítica coloca em movimento o estabelecimento de cada fato e de cada conexão. Dizendo em termos gerais, se trata de uma cientificidade que nunca perde sua ligação com a colocação espontaneamente ontológica da vida cotidiana, que, antes a purifica criticamente e a desenvolve elevando-a e as determinações ontológicas que necessariamente fundamentam toda ciência, as elabora conscientemente. Nisso precisamente instala claramente sua contradição com toda filosofia que constrói logicamente ou como quer que seja (LUKÁCS, 2007, p. 77).
\end{abstract}

A busca de pontos de contato entre a epistemologia ambiental e a teoria lukacsiana é uma proposta metodológica a alavancar iniciativas para desconstruir e enfrentar a crise do conhecimento dada a possibilidade de engendrar novos focos de reflexão, novas facetas de análise, novas formas de expressão no diálogo que se estabelece com diferentes pesquisadores, como empreende Leff (2007):

O saber ambiental promove diálogo entre Marx e Heidegger, entre Althusser e Derrida, entre Foucault e Lévinas, nas margens do pensamento estabelecido; 


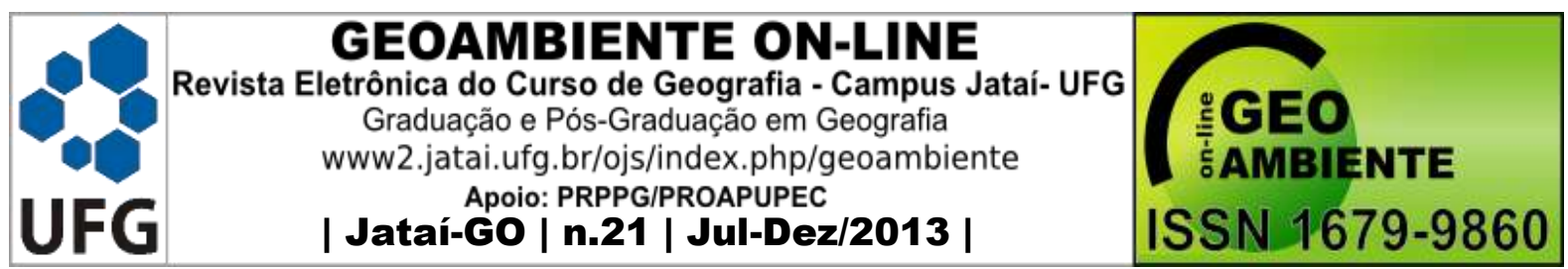

questiona o conhecimento a partir de fora do campo de positividade em que se apresenta a coisa, o ente e o logos, a partir da exterioridade da qual observa o confinamento de todo pensamento que aspira à unidade, à universalidade e à totalidade: da episteme estruturalista e da teoria de sistemas até a ontologia de um ser genérico e a ecologia generalizada como "ciência as ciências". [...] O saber ambiental vai derrubando certezas e abrindo os raciocínios fechados que expulsam o ambiente dos círculos concêntricos do conhecimento. A epistemologia ambiental confronta o projeto positivista (universal, objetivo) do conhecimento e deslinda as estratégias de poder que se entrelaçam nos paradigmas científicos e na racionalidade da modernidade. Esta é sua coerência estratégica. A epistemologia ambiental é uma política do saber que busca a sustentabilidade da vida (LEFF, 2007, p. 13-14. Grifos no original).

É imperiosa e desafiadora a construção de uma epistemologia ambiental aproximandoa, o quanto possível, da teoria lukacsiana como forma de desconstruir o pensamento fetichizado e impulsionar interpretações sobre o avanço do capitalismo como sistema que se aprimora cada vez mais em saquear os recursos naturais pela produção da mercadoria e gerir lucro como fluxo vital. O capital que se mantém do saque sobre as reservas ambientais deixa incerta a sobrevivência das futuras gerações. A defesa dele, muitas vezes é empreendida por cientistas que optaram por "biologizar a indústria" como pretende explicar Morin (2010):

Os poderes criados pela atividade cientifica escapam totalmente aos próprios cientistas. Esse poder, em migalhas no nível da investigação, encontra-se reconcentrado no nível dos poderes econômicos e políticos. De certo modo, os cientistas produzem um poder sobre o qual não têm poder, mas que enfatiza instâncias já todo-poderosas, capazes de utilizar completamente as possibilidades de manipulação e de destruição provenientes do próprio desenvolvimento da ciência (MORIN, 2010, p. 18).

As análises de Morin contribuem de maneira tácita na direção do esforço em encontrar intercepções da epistemologia ambiental com a teoria lukácsiana cuja proposta metodológica faz desses apontamentos apenas uma iniciativa. De acordo com Morin (2010) tornou-se urgente a liberação do controle da ciência do processo de atrelamento via subvenção e fomento advindos dos cofres capitalistas e estatais. Ele entende que

$\mathrm{Na}$ origem, os investigadores eram amadores no sentido primitivo do termo: eram ao mesmo tempo filósofos e cientistas. A atividade científica era sociologicamente marginal, periférica. Hoje, a ciência tornou-se poderosa e maciça instituição no centro da sociedade, subvencionada, alimentada, controlada pelos poderes econômicos e estatais. [...] Os interesses econômicos, capitalistas, o interesse do Estado desempenham seu papel ativo nesse circuito de acordo com suas finalidades, seus programas, suas subvenções. A instituição científica suporta as coações tecnoburocráticas próprias dos grandes aparelhos econômicos ou estatais, mas nem o Estado, nem a indústria, nem o capital são guiados pelo espírito científico: utilizam os poderes que a investigação cientifica lhes dá[...].O pensamento de Adorno e Habermas recorda-nos incessantemente que a enorme massa do saber quantificável e tecnicamente utilizável não passa de veneno se for privado da força libertadora da reflexão (MORIN, 2010, p. 19-21). 


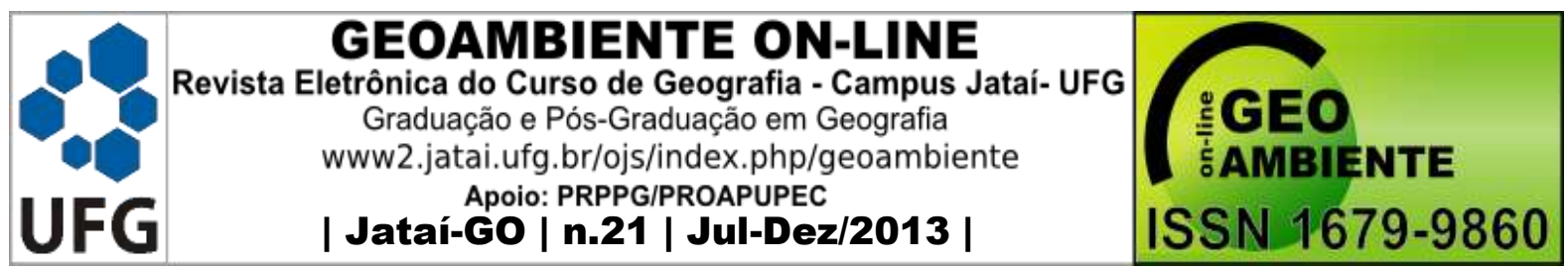

Esse veneno a que se refere Morin (2010) é a miséria da razão identificada por Coutinho (2010) e que se difunde por intermédio do pensamento fetichizado que só poderá ser desfeito à medida que os pesquisadores forem construindo uma cientificidade priorizando nela o desenvolvimento do mais alto nível de consciência como explica Lukács (2007):

\begin{abstract}
Ciência pode facilmente sair de sua função de controle e converter-se em órgão de ocultação, de desaparição da essência, no sentido que Hobbes conheceu. Por isso não é casual que a afirmação de Marx sobre a ciência e sobre a relação do fenômeno e da essência se escrevesse num marco de critica da economia vulgar, na polêmica com concepções e interpretações de formas fenomênicas, absurdas - desde o ponto de vista do ser - e que suplantam inteiramente as conexões reais. A afirmação filosófica de Marx, tem aqui a função de uma crítica ontológica das falsas representações, de um despertar da consciência cientifica, com o fim de restabelecer no pensamento a autentica realidade em si. [...] Por nossa parte cremos que Marx nisso tem criado uma nova forma de cientificidade geral, como também de ontologia, destinada no futuro a superar o carácter profundamente problemático da cientificidade moderna (LUKÁCS, 2007, p. 80).
\end{abstract}

A desconstrução do carácter problemático da cientificidade moderna tem sua gênese no desenvolvimento da racionalidade cientifica por um alto nível de consciência impulsionando a necessária força libertadora da reflexão. Portanto, é necessária a crítica ao pensamento fetichizado como resultado do avanço capitalista, contudo, insuficiente se, simultaneamente, não se buscar alternativas críveis e viáveis para fazer frente ao modelo capitalista de desenvolvimento.

\title{
A superação do pensamento fetichizado
}

A insustentável racionalidade da economia de mercado cuja manifestação impede o reconhecimento da gênese da degradação ambiental como resultado da acumulação capitalista é impulsionado pelo pensamento fetichizado, que será superado na medida em que se construir uma epistemologia ambiental concebendo os impactos ambientais como conseqüência do avanço capitalista. Várias análises podem ampliar a compreensão nessa direção, como por exemplo, as de Leff (2007; 2013); Löwy (2012); Sachs (2008); Sampaio (2010), entre outros. Todavia as análises de Lukács (2007) são imprescindíveis por elucidar a gênese do pensamento fetichizado ao desenvolver a ontologia do ser social. No Brasil foi Coutinho (2010) um dos principais responsáveis pela divulgação da obra lukacsiana e, nesses apontamentos suas contribuições auxiliarão na tarefa de encontrar possíveis pontos de contato entre a epistemologia ambiental e a teoria lukacsiana.

A teoria de Lukacs esclarece que a construção "de uma ontologia materialista da 


\begin{tabular}{|c|c|c|}
\hline & $\begin{array}{c}\text { GEOAMBIENTE ON-LINE } \\
\text { Revista Eletrônica do Curso de Geografia - Campus Ja } \\
\text { Graduacăo e Pós-Graduaçăo em Geografia } \\
\text { www2.jatai.ufg.br/ojs/index.php/geoambient } \\
\text { Apoio: PRPPG/PROAPUPEC } \\
\text { | Jataí-GO | n.21 | Jul-Dez/2013 | }\end{array}$ & $\begin{array}{l}\text { BIENTE } \\
1679-9860\end{array}$ \\
\hline
\end{tabular}

natureza, que compreende sua historicidade, processualidade e contraditoriedade dialética está contida implicitamente na fundamentação metodológica da ontologia de Marx" (LUKÁCS, 2007, p. 74). E, conseqüentemente, pode contribuir com o entendimento de que determinados esforços humanos impulsionados pela espontaneidade e imediaticidade são "incapazes de recompor no pensamento a essência dialética da objetividade [...]” e, são, portanto, "encarnações de um pensamento imediatista, incapaz de atingir a essência do objeto" (COUTINHO, 2010, p. 43-44).

A imediaticidade do pensamento fetichizado concorre para obstaculizar a compreensão da degradação ambiental como conseqüência do avanço do capital, pois, além de não conseguir separar fenômeno de essência, não consegue estabelecer, de forma adequada e lógica, um liame causal entre os impactos ambientais e a expansão capitalista. As manifestações do pensamento fetichizado são como anteparos a impedir o reconhecimento da gênese dessa degradação ambiental ao fazer coincidir, de maneira imediata, o fenômeno e a essência.

Entre as análises que trataram de desvencilhar a identidade entre fenômeno e essência ganham destaques aquelas desenvolvidas por Lukács (2007). Porém, antes de analisar tais contribuições é importante conhecer os estudos de Kosik (1985) e Khun (2009), pois se constituem análises consolidadas que podem corroborar na compreensão e auxiliar com suas reflexões a superar o pensamento fetichizado.

Para Kosik (1985) a exigência em se transitar do fenômeno para a essência é desafiadora, ardilosa e obstinada, pois, no desenvolvimento da vida humana é possível constatar duas abordagens: a existência da realidade dos fatos e a existência da representação deles. A primeira é imutável e histórica, a segunda pode ser alterada conforme a intencionalidade de quem criou a representação. Portanto, é passível de se averiguar duas realidades: uma fática e outra midiática, aquela que está vinculada nos periódicos e demais meios de comunicação social.

As mídias vivem dos medos, demonstram as análises de Martin-Barbero e Rey (2001), ao estudar a relação dos seres humanos com o real. Procuram diagnosticar as mediações que se dão entre as lógicas de produção e as lógicas de recepção, entre as matrizes culturais e os formatos industriais. Discutem o poder da televisão sobre o imaginário das pessoas. Entendem que a virtualidade e a construção dos simulacros ocupam as relações sociais de antes, quando eram desenvolvidas pelas práxis diretas e/ou indiretas. Essa substituição propicia as condições 


\begin{tabular}{|c|c|c|}
\hline & $\begin{array}{c}\text { GEOAMBIENTE ON-LINE } \\
\text { Revista Eletrônica do Curso de Geografia - Campus Ja } \\
\text { Graduacăo e Pós-Graduaçăo em Geografia } \\
\text { www2.jatai.ufg.br/ojs/index.php/geoambient } \\
\text { Apoio: PRPPG/PROAPUPEC } \\
\text { | Jataí-GO | n.21 | Jul-Dez/2013 | }\end{array}$ & $\begin{array}{l}\text { BIENTE } \\
1679-9860\end{array}$ \\
\hline
\end{tabular}

sociais por meio das quais, facilmente pode ser confundidas a manifestação fenomênica da realidade com a sua essência.

Para distingui-las Kosik (1985) explica que a realidade não se apresenta aos seres humanos à primeira vista. É o indivíduo que a partir de sua situação "cria suas próprias representações das coisas e elabora todo um sistema correlativo de noções que capta e fixa o aspecto fenomênico da realidade" (KOSIK, 1985, p. 10). Pela percepção, o aspecto fenomênico da realidade é captado pelo ser humano de forma imediata e se desenvolve pelo pensamento concreto. $\mathrm{O}$ aspecto aparente e fenomênico é necessário, mas insuficiente, pois;

captar o fenômeno de determinada coisa significa indagar e descrever como a coisa em si se manifesta naquele fenômeno, e como ao mesmo tempo nele se esconde. Compreender o fenômeno é atingir a essência. Sem o fenômeno, sem a sua manifestação e revelação, a essência seria inatingível (KOSIK, 1985, p.12. Grifos no original).

O desenvolvimento do cosmo humano consiste na ininterrupta atividade visando a produção de sentidos tentando encontrar a essência para compreender as contradições que lhes são inerentes. Na pesquisa, a trajetória necessária a ser percorrida da aparência para a essência é antecipada com a escolha prévia dos fenômenos a serem analisados como previu Khun (2009). Segundo suas análises, o pesquisador seleciona antecipada e intencionalmente os fenômenos que analisará, pois aqueles fenômenos "que não se ajustam aos limites do paradigma freqüentemente nem são vistos" (KHUN, 2009, p. 45).

O paradigma designado por Khun (2009) consiste na intencionalidade e na incomensurabilidade de sua maneira de ver o mundo, porque elas são as principais bases que definem o paradigma e o determinam, uma vez que, "o que um homem vê depende tanto daquilo que ele olha como daquilo que sua experiência visual-conceitual prévia o ensinou a ver” (KHUN, 2009, p. 150). Já que “o cientista não pode apelar para algo que esteja aquém ou além do que ele vê com seus olhos e instrumentos" (KUHN, 2009, p. 151). O paradigma fornecerá maior amplitude ao aparato cultural, que, no ser humano funciona como se fossem "lentes, através das quais os homens vêem, o meio através do qual interpretam e informam o que vêem” (SHANNIN, 1983, p. 194).

O paradigma como modelo tem a finalidade de orientar as pesquisas e, estabelecer, aproximadamente, o campo de estudo e seus limítrofes, eleger determinados fenômenos para serem analisados "dentro dos limites preestabelecidos e relativamente inflexíveis fornecidos pelo paradigma" (KHUN, 2009, p.44). Esses limites preestabelecidos também fazem parte do 


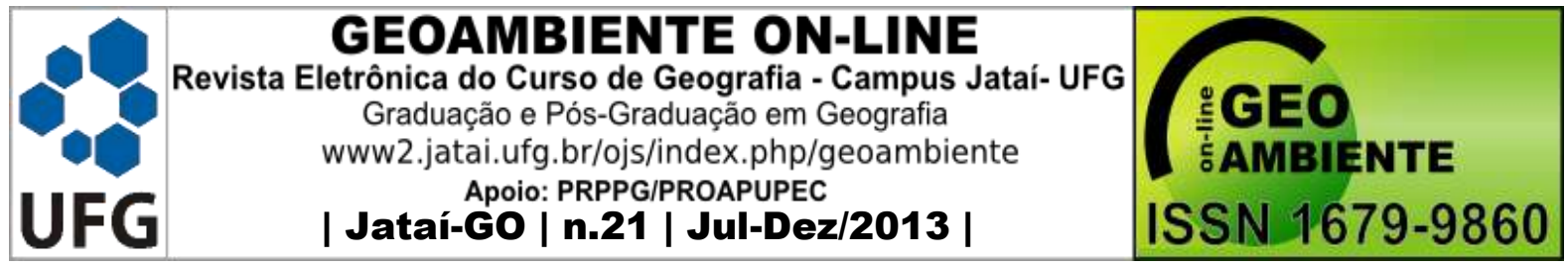

arcabouço teórico do pesquisador determinando, antecipadamente, a abrangência da sua análise.

Como protótipo ideal, como um modelo em construção, o paradigma atrai um grupo duradouro de partidários e permanece aberto "para deixar toda a espécie de problemas para serem resolvidos pelo grupo redefinido de praticantes da ciência” (KHUN, 2009, p. 30). Por conseguinte, "a pesquisa científica normal está dirigida para a articulação daqueles fenômenos e teorias já fornecidos pelo paradigma" (p.45). O paradigma fornece suporte científico para as pesquisas, seja dirigindo-as, "seja modelando-as diretamente, seja através de regras abstratas" (p. 72).

Ao reunir nos seus domínios: métodos, proposições, problemas, regras, pressupostos, interpretações, visões de mundo e padrões de solução, o paradigma gera, inevitavelmente, debates freqüentes entre os pesquisadores por causa da busca do conhecimento científico. Ao surgir fenômenos novos e não previstos que são descobertos pela pesquisa científica, os quais não mais se ajustam aos limites definidos por aquele paradigma, exige então, a elaboração de um novo conjunto de padrões e regras, constituindo um novo modelo, um novo paradigma como explica Khun (2009):

\begin{abstract}
A descoberta começa com a consciência da anomalia, isto é, com o reconhecimento de que, de alguma maneira, a natureza violou as expectativas paradigmáticas que governam a ciência normal. Segue-se então uma exploração mais ou menos ampla da área onde ocorreu a anomalia. Esse trabalho somente se encerra quando a teoria do paradigma for ajustada, de tal forma que o anômalo se tenha convertido no esperado. A assimilação de um novo tipo de fato exige mais do que um ajustamento aditivo da teoria. Até que tal ajustamento tenha sido completado - até que o cientista tenha aprendido a ver a natureza de um modo diferente o novo fato não será considerado completamente científico (KHUN, 2009, p. 78).
\end{abstract}

É importante ressaltar que anomalia para Khun é compreendido como superação numa perspectiva linear em que o paradigma anterior é, necessariamente, removido e substituído. Porém, para a epistemologia ambiental cujos impactos ambientais são conseqüências da reprodução do capital social total a anomalia será considerada como disputa numa perspectiva paralela em que o paradigma anterior é negado, mas não substituído. Enquanto para Khun(2009) um paradigma nega e substitui o outro, para esses apontamentos, um paradigma nega, mas não substitui o outro. E a existência dos dois paradigmas é extremamente importante pela possibilidade de estabelecer o debate paradigmático entre eles como condição de aproximação da realidade ambiental.

Somam-se às análises de Kosik (1985) e Khun (2009) as desenvolvidas por Luckács 


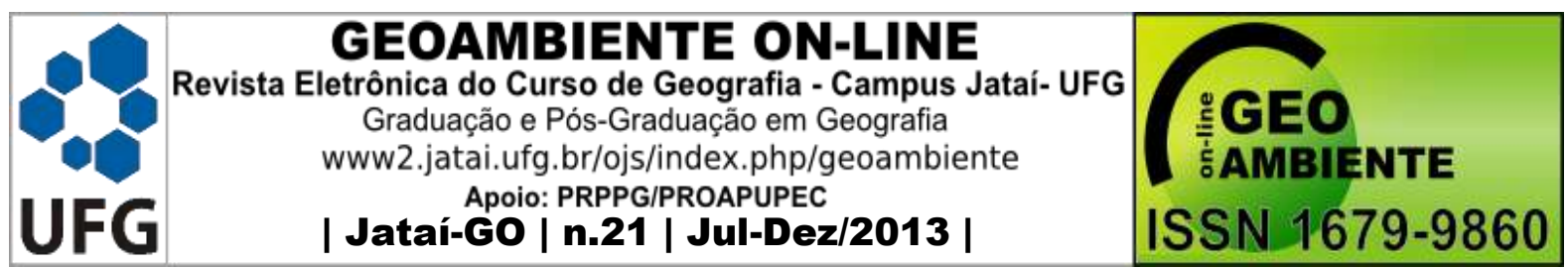

(2007) as quais trataram de desvencilhar a identidade entre fenômeno e essência refletindo sobre a ontologia do ser social em Marx. Para Lukács

a ciência surge da vida e por muito que o separamos e o desejamos, devemos nos comportar na vida com espontaneidade ontológica [...] se trata de uma cientificidade que nunca perde sua ligação com a colocação espontaneamente ontológica da vida cotidiana, que pelo contrário a purifica criticamente e a desenvolve elevando-a a determinações ontológicas que necessariamente fundamentam toda ciência e as elabora conscientemente (LUKÁCS, 2007, p. 77).

E mais,

\begin{abstract}
Precisamente nos problemas do ser social, a questão ontológica da diferença, da contradição e do nexo entre fenômeno e essência, desempenha um papel decisivo. Com frequiência, na vida cotidiana, os fenômenos ocultam a essência de seu próprio ser, em lugar de revelá-la. [...] Por isso o enunciado de Marx de que "toda ciência seria supérflua, se a forma fenomênica e a essência das coisas coincidissem de maneira imediata" é extraordinariamente importante para a ontologia do ser social. $\mathrm{O}$ principio em si e por si ontologicamente geral, se refere tanto à natureza como a sociedade (LUKÁCS, 2007, p. 78-79).
\end{abstract}

A superação do pensamento fetichizado e decadente dependerá da capacidade interpretativa, da qual a epistemologia ambiental pode se tornar parte inerente, se conseguir inverter a inversão que mantém a realidade invertida e, cada vez mais, ampliada pelas atuais redes sociais incrementando as relações fetichizadas as quais empobrece a razão humana e essa "miséria da razão transforma em algo irracional todos os momentos significativos da vida humana" (COUTINHO, 2010, p. 43).

A progressiva decadência vem se expandindo, na historia da filosofia burguesa, com ruptura radical da razão humanista e dialética que "vai dos pensadores renascentistas a Hegel" (COUTINHO, 2010, p. 21). Para Coutinho (2010) a racionalidade humanista, historicista e dialética foi desenvolvida pela construção de três categorias imprescindíveis como a razão dialética, a dimensão histórica da objetividade e da riqueza humanista da práxis, constituindo os "únicos instrumentos capazes de fundar cientificamente a ética e a ontologia" (COUTINHO, 2010, p.30).

Ao serpentear as relações sociais o capital suscita, por intermédio desses fluxos, relações fetichizadas, engendradas cotidianamente pelas práxis indireta. Elas necessariamente são intermediadas pela comoditização do fetiche cada vez mais sedutor, que, do interior da mercadoria, impede o ser humano de se reconhecer como produto de sua própria atividade histórica e coletiva. Eis, portanto, a gênese do pensamento fetichizado. Ao emergir e evoluir vai "endeusando" o capitalismo que se sustenta por causa da sua enorme produtividade a qual, muitas vezes, é utilizada como anteparo impedindo o reconhecimento e a identificação de 


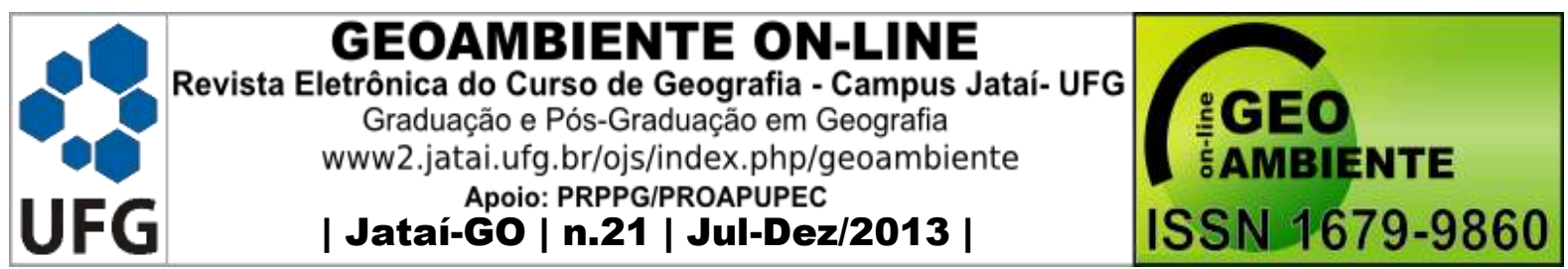

suas contradições geradas em seu entorno, como demonstraram as análises de Coutinho (2010) que serão vistas mais adiante.

O incensamento da enorme eficiência produtiva do capital impulsionado pelo avassalador desenvolvimento tecnológico do seu parque industrial, além de empobrecer a ação humana - empobrecimento que Coutinho (2010) denomina de miséria da razão - não contribui para o reconhecimento da importância do cidadão como um ser social - muito mais importante do que as dimensões financeiras - e, muito mais complexo e articulado, pois,

\begin{abstract}
Essa fetichização simultânea do sujeito e do objeto, paralela à ruptura dos laços imediatos entre indivíduo e comunidade, é a mais evidente conseqüência social da divisão capitalista do trabalho em sua fase madura. Entra aqui em jogo uma complicada dialética de essência e aparência, cujas conseqüências cognoscitivas são da maior importância para o processo que pretendemos descrever. Aparência e essência são momentos constitutivos da realidade objetiva. Todavia, entre esses dois níveis do real pode sempre existir, em maior ou menor intensidade, uma contradição ou mesmo um antagonismo. Uma representação cientifica da realidade, bem como uma práxis ampla e eficaz, demandam o estabelecimento de uma mediação dialética entre os mesmos, na qual a aparência seja dissolvida na totalidade que revela a essência.

[...] Quando o pensamento não tem condições de superar o imediatismo e o espontaneísmo, não pode superar a descrição da forma aparente e alcançar a reprodução da essência. Converte então essa forma aparente em fetiche, ao conceder-lhe uma autonomia e universalidade que não possui (COUTINHO, 2010, p. 37-38).
\end{abstract}

O fetiche como parte inerente da mercadoria se assemelha a um discurso destituído de significado, pois a essência está num lugar e o fenômeno em outro. Com freqüência, os fenômenos servem para dissimular a essência do seu próprio ser, obscurecendo a compreensão, como aquele obscurecimento causado pela luz do sol em relação ao brilho das estrelas que, durante o dia, é imperceptível, mas é explicito à noite.

Essa constatação subjetiva pode ser também descrita quanto à imediaticidade que ocorre com os fatos econômicos. Trata-se da incompetência do pensamento fetichizador assim descrito por Coutinho (2010):

\footnotetext{
A incapacidade de atingir a essência surge espontaneamente em todos os indivíduos que vivem no capitalismo evoluído. Ao submeter-se a esse espontaneísmo, a filosofia da decadência cai na mesma incapacidade: termina por converter em antinomias algumas contradições dialéticas e por elevar a fetiches coagulados momentos isolados de uma totalidade contraditória. Esse traço essencial do pensamento decadente - o de ser um pensamento fetichizador - manifesta-se em todas as suas orientações, "racionalistas" e irracionalistas, "objetivistas" ou subjetivistas, positivistas ou existencialistas. Nenhuma delas transcende a mera descrição da imediaticidade (COUTINHO, 2010, p. 39).
}

Para transcender a mera descrição da imediaticidade faz-se necessário desvendar e desvencilhar os fenômenos interpretando neles o que é mera aparência da sua mais profunda 


\begin{tabular}{|c|c|c|}
\hline & $\begin{array}{c}\text { GEOAMBIENTE ON-LINE } \\
\text { Revista Eletrônica do Curso de Geografia - Campus Ja } \\
\text { Graduacăo e Pós-Graduaçăo em Geografia } \\
\text { www2.jatai.ufg.br/ojs/index.php/geoambient } \\
\text { Apoio: PRPPG/PROAPUPEC } \\
\text { | Jataí-GO | n.21 | Jul-Dez/2013 | }\end{array}$ & $\begin{array}{l}\text { BIENTE } \\
1679-9860\end{array}$ \\
\hline
\end{tabular}

essência sendo essa a mais importante atividade de quem desenvolve pesquisa científica, como anteriormente foi explicitado por Khun (2009).

A superação do pensamento fetichizado e decadente dependerá da capacidade interpretativa, da qual a epistemologia ambiental é parte inerente, se conseguir inverter a inversão que mantém a realidade invertida e, cada vez mais, ampliada pelas redes sociais. As redes sociais exercem funções semelhantes que outrora foram estabelecidas pelo intenso processo de burocratização descrita por Max Weber e, por isso, fetichiza cada vez mais os elementos da ação humana cujo "caráter repetitivo da ação burocratizada bloqueia o contato criador do homem com a realidade, substituindo a apropriação humana do objeto por uma manipulação vazia de "dados", segundo esquemas formais estabelecidos", como procurou explicitar Coutinho (2010, p. 40-41).

A degradação ambiental se acirrou a partir do desenvolvimento da sociedade organizada como suporte para o avanço do capital impulsionando as desigualdades sociais sustentando dois mundos distintos: o da opulência e o da miséria, como já foi dito antes. A organização dessa sociedade se apóia no mundo da mercadoria onde as relações sociais estão cada vez mais fetichizada, como enfatiza Santos $(2004 ; 2006)$, onde o dinheiro é que define o território.

\section{Considerações finais}

Diante da insustentável racionalidade da economia de mercado novas compreensões e concepções emergirão na medida em forem problematizados os paradigmas que dão sustentabilidade teórica, política e econômica ao modelo de desenvolvimento produtivistaconsumista implantado no globo. Até que ponto é possível afirmar que esse modelo capitalista está na origem da questão ambiental? Historicamente é possível provar que o capital sempre encontrou um modo peculiar de se reproduzir e para que isso ocorresse, utilizou ilimitadamente os recursos naturais esquadrinhando todo o globo a fim de obter os melhores e mais baratos meios de produção.

A questão ambiental assim compreendida ainda não foi devidamente incorporada no debate sobre o desenvolvimento principalmente na América Latina. Nela ainda persiste a discussão sobre crescimento econômico, justiça social e participação política. São razões como essas que justificam ainda serem precárias as teorias, as metodologias e os modelos interpretativos. 


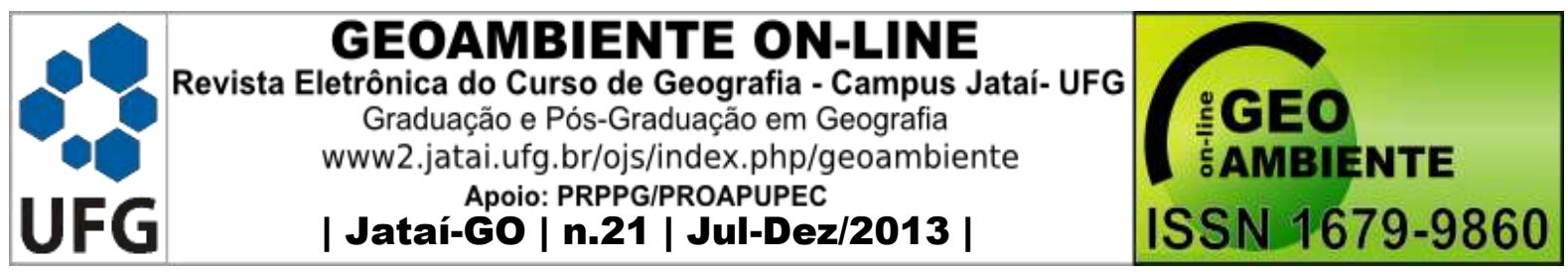

Para elencar alternativas capazes de problematizar e impulsionar o debate esse texto defende a importância da construção de uma ciência com consciência e com estratégias utópicas capazes de matar a morte engendrada pelo veneno "científico" apontado por Morin (2010, p. 21). O veneno cientifico, como miséria da razão, se amplia por intermédio do pensamento fetichizado. Ao desfazer e desconstruir o pensamento fetichizado o ser humano retoma sua inerente capacidade de sonhar, de almejar "algo" impossível, não aceitando passivamente ser apenas mais um componente de uma sociedade sem propósito, sem utopia, mas defender a hipótese de que uma outra sociedade é possível. A palavra final não está com o capital.

\section{Referências}

ARRIGHI, Giovanni. O longo século XX Dinheiro, Poder e AS Origens de Nosso Tempo $7^{\mathrm{a}}$ impressão. Rio de Janeiro: Contraponto, 2009.

BOURDIEU, Pierre. Contrafogos 2. Rio de Janeiro: Jorge Zahar Editor, 2001.

CARSON, Rachel. Primavera Silenciosa. $3^{\text {a }}$ reimp. São Paulo: Editora Gaia, 2013.

COUTINHO. Carlos Nelson. O Estruturalismo e a Miséria da razão. $2^{\mathrm{a}}$ e. São Paulo: Editora Expressão Popular, 2010.

DUSSEL, Enrique. Ética da Libertação na idade da globalização e da exclusão. Petrópolis: Vozes, 2000.

HARVEY, David. The Enigma Of Capital and The Crises Of Capitalism. New York: Oxford University Press, 2010.

KAUTSKY, Karl. A questão agrária.São Paulo: Nova Cultural, 1986.

KOSIK, Karel. Dialética do Concreto. $3^{\text {a }}$ ed. Rio de Janeiro: Editora Paz e Terra, 1985.

KUHN, Thomas S. A Estrutura das Revoluções Científicas. $9^{\mathrm{a}}$ ed. $1^{\mathrm{a}}$ reimpressão. São Paulo: Editora Perspectiva, 2009.

LEFF, Enrique. Complexidade, Interdisciplinaridade e Saber Ambiental. In: Interdiciplinaridade em Ciências Ambientais, PHILIPPI JUNIOR, Arlindo, TUCCI, C.E.M., HOGAN, D.J., NAVEGANTES, Raul (editores), São Paulo: Signus, 2000, p. 19-51.

LEFF, Enrique. Epistemologia Ambiental. 4a edição revista. São Paulo: Cortez Editora, 2007. LEFF, Enrique. Ecologia Política: uma perspectiva latino-americana. Desenvolvimento e Meio Ambiente, volume 27, jan/jun. 2013, p. 11-20. 


\begin{tabular}{|c|c|c|}
\hline & $\begin{array}{c}\text { GEOAMBIENTE ON-LINE } \\
\text { Revista Eletrônica do Curso de Geografia - Campus Ja } \\
\text { Graduacăo e Pós-Graduaçăo em Geografia } \\
\text { www2.jatai.ufg.br/ojs/index.php/geoambient } \\
\text { Apoio: PRPPG/PROAPUPEC } \\
\text { | Jataí-GO | n.21 | Jul-Dez/2013 | }\end{array}$ & $\begin{array}{l}\text { BIENTE } \\
1679-9860\end{array}$ \\
\hline
\end{tabular}

LÖWY, Michel. Ecossocialismo: alternativa de desenvolvimento para superar o modelo produtivista-consumista. In: Revista ABONG: Organizações em Defesa dos Direitos e Bens Comuns, 2012, p.7-15.

LUKÁCS, György. Marx, Ontologia Del Ser Social. Madrid: Ediciones Akal, 2007.

LUXEMBURG, Rosa. A Acumulação do Capital. São Paulo: Nova Cultural, 1985.

MORIN, Edgar. Ciência com Consciência. 13 $3^{\mathrm{a}}$ edição. Rio de Janeiro: Bertrand Brasil, 2010.

SANTOS, Milton. Território e Sociedade. $2^{\mathrm{a}}$ reimp. São Paulo: Editora Fundação Perseu Abramo, 2004.

SANTOS, Milton e BECKER, Berta. Território, territórios. Ensaios sobre o ordenamento territorial. 2a edição. Rio de Janeiro: DP\&A, 2006.

SEN, Amartya. Desenvolvimento como liberdade. $7^{\mathrm{a}}$ impr. São Paulo: Companhia das Letras, 2008 .

SHANIN, Teodor. La classe Incomoda. Alianza Editorial: Madrid, 1983.

SÓGLIO, Fábio Kessler Dal. O Desenvolvimento Rural no Brasil e na América Latina: como estão nossos projetos. In: Desenvolvimento Rural no Cone Sul. Desarrollo Rural en el Cono Sur, ALMEIDA, Jalcione e MACHADO, J.A.D. (orgs.) Porto Alegre: Associação Holos Meio Ambiente e Desenvolvimento (e-book), 2009, p. 311-336. 